\title{
An Apparatus for Performing Microtensile Tests at Elevated Temperatures inside a Scanning Electron Microscope
}

\section{Citation}

Sim, Gi-Dong, Jun-Hyub Park, Michael D. Uchic, Paul A. Shade, Soon-Bok Lee, and Joost J. Vlassak. 2013. An apparatus for performing microtensile tests at elevated temperatures inside a scanning electron microscope. Acta Materialia 61, no. 19: 7500-7510.

\section{Published Version}

doi:10.1016/j.actamat.2013.08.064

\section{Permanent link}

http://nrs.harvard.edu/urn-3:HUL.InstRepos:34901219

\section{Terms of Use}

This article was downloaded from Harvard University's DASH repository, and is made available under the terms and conditions applicable to Open Access Policy Articles, as set forth at http:// nrs.harvard.edu/urn-3:HUL.InstRepos:dash.current.terms-of-use\#OAP

\section{Share Your Story}

The Harvard community has made this article openly available.

Please share how this access benefits you. Submit a story.

\section{Accessibility}




\title{
An apparatus for performing micro-tensile tests at elevated temperatures inside a scanning electron microscope
}

Gi-Dong Sim ${ }^{\mathrm{a}, \mathrm{d}}$, Jun-Hyub Park ${ }^{\mathrm{a}, \mathrm{b}}$, Michael D. Uchic ${ }^{\mathrm{c}}$, Paul A. Shade ${ }^{\mathrm{c}}$, Soon-Bok Lee ${ }^{\mathrm{d}}$, Joost J. Vlassak ${ }^{\mathrm{a}, *}$

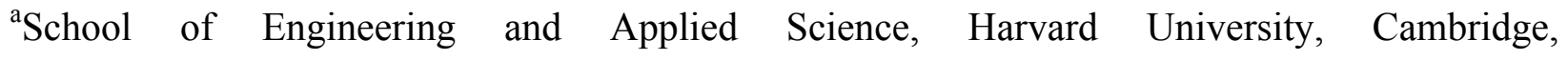
Massachusetts 02138, USA

${ }^{b}$ Department of Mechatronics Engineering, College of Engineering, Tongmyong University, 535, Yongdang-Dong, Nam-Gu, Busan 608-711, Republic of Korea

${ }^{c}$ Air Force Research Laboratory, Materials and Manufacturing Directorate, 2230 10th Street, Wright-Patterson AFB, OH 45433, USA

${ }^{\mathrm{d}}$ Department of Mechanical Engineering, KAIST, 291 Daehak-ro, Yuseong-gu, Daejeon 305-701, Republic of Korea

\begin{abstract}
In this paper, we introduce an apparatus to perform micro-tensile tests at elevated temperatures inside a scanning electron microscope. The apparatus has a stroke of 250 $\mu \mathrm{m}$ with a displacement resolution of $10 \mathrm{~nm}$ and a load resolution of $9.7 \mu \mathrm{N}$. Measurements at elevated temperatures are performed through use of two silicon-based micromachined heaters that support the sample. Each heater consists of a tungsten heating element that also serves as a temperature gauge. To demonstrate the testing capabilities, tensile test were performed on submicron $\mathrm{Cu}$ films at various temperatures up to $430^{\circ} \mathrm{C}$. Stress-strain curves show a significant decrease in yield strength and initial slope for the samples tested at elevated temperature, which we attribute to diffusionfacilitated grain boundary sliding and dislocation climb.
\end{abstract}

Keywords: In situ tension test, High-temperature deformation, Thin film, Grain boundary sliding, Creep

\footnotetext{
* Corresponding author.

Tel.: +1 617496 0424; fax: +1 617495 9837;

e-mail address: vlassak@seas.harvard.edu;
} 


\section{Introduction}

Thin metal films with thicknesses well below $1 \mu \mathrm{m}$ are widely used as functional and structural elements in microelectronic devices and large-scale integrated circuits, thin-film solar cells [1], electrical sensors [2, 3], and electronic textiles [4]. Decreasing dimensions of micro-electronic and micro-mechanical devices have motivated research on the microand nano-scale mechanical behavior of materials. Much work has been dedicated to characterizing the mechanical behavior of thin metal films and it has been observed that the mechanical properties of thin films can be very different from those of their bulk counterparts. For example, experimental studies have shown that the flow stress, hardening rate and fatigue life exhibit a strong size-dependence [5-13]. With conventional mechanical testing methods used for bulk materials it is difficult to obtain precise stressstrain curves for thin films and capture this size-dependence. Much attention has consequently been directed toward experimentally measuring the mechanical properties of thin films by a variety of techniques [14-17]. Most of these studies successfully investigated the effects of microstructural length scales and sample size on the mechanical properties of thin films at room temperature. Length-scale effects at elevated temperatures remain an unexplored area.

Prior studies of the mechanical behavior of thin films at elevated temperatures focused on films deposited on substrates [18-22]. However, recent work has revealed that the tensile and fatigue behavior of metallic thin films on substrates may differ substantially from the behavior of freestanding thin films [6, 23-26]. Thus, testing freestanding thin films at elevated temperature is a critical step towards understanding their intrinsic behavior. 
Testing of freestanding thin films has historically been challenging due to the inherent difficulties associated with handling and gripping of the samples. The basic requirements for accurate elevated temperature mechanical testing, including a uniform temperature distribution throughout the sample, accurate measurement of the temperature, and a controlled environment to prevent sample oxidation, are further complicated by the small sample dimensions. As a result, only a few studies report mechanical testing of freestanding thin films at elevated temperatures [27-34]. These studies expanded our understanding, but were limited to films with thicknesses above several microns [30-33] or to temperatures lower than $200{ }^{\circ} \mathrm{C}[27-29,34]$.

In this paper, we present a tensile tester with $9.7 \mu \mathrm{N}$ load resolution and $10 \mathrm{~nm}$ displacement resolution that can be used inside a SEM. Measurements at elevated temperatures are performed through use of two silicon-based micromachined heaters that support the sample. Each heater consists of a tungsten heating element that also serves as a resistance thermometer. To demonstrate the testing capabilities, tensile tests were performed on submicron $\mathrm{Cu}$ films at various temperatures up to $430^{\circ} \mathrm{C}$. 


\section{Tester description and thermal modeling}

\subsection{In-situ SEM tensile tester and calibration}

The tensile tester was designed to cover a broad range of displacements (tens of $\mathrm{nm}$ to hundreds of $\mu \mathrm{m}$ ) and loads (tens of $\mu \mathrm{N}$ to $10 \mathrm{~N}$ ), and to work inside the chamber of a scanning electron microscope (SEM). These design requirements were met through use of capacitive displacement gauges and a load cell that consisted of a compliant double leaf spring. The tester is shown schematically in Fig. 1. As illustrated in the figure, an $\mathrm{XYZ}$-axis micro stage is used to align tester and sample. The sample is deformed using a piezo nano-positioning actuator (PI P-622K067) with an external amplifier/servo controller for closed-loop control (PI E-665). This actuator is capable of imposing displacements as large as $250 \mu \mathrm{m}$ with a resolution better than $10 \mathrm{~nm}$. The actuator displacement, $\delta_{1}$, scales with the voltage applied to the actuator and is measured using an internal displacement sensor. As the sample is loaded, the leaf spring deforms and the displacement of the spring, $\delta_{2}$, is measured using a capacitive displacement sensor (Capacitec HPB-200A). This displacement sensor has a working range of $600 \mu \mathrm{m}$ and a resolution of $10 \mathrm{~nm}$. The load on the sample is determined from the displacement of the leaf spring and its spring constant $k$. To prevent interference by the electron beam inside the SEM, the displacement sensor is shielded by an aluminum enclosure.

The displacement imposed on the sample is given by the difference between the displacement of the actuator and that of the leaf spring,

$$
\delta=\delta 2-\delta 1
$$

while the load on the sample is given by 
$F=k \cdot \delta 2$.

To calibrate the leaf spring, a $98 \mathrm{mN}$ load cell (Cooper instruments \& systems LFS $27010 \mathrm{G})$ was attached to the tester and the load-displacement characteristic of the leaf spring was measured. The spring was linear to within $99.7 \%$ for loads up to $0.098 \mathrm{~N}$ and had a spring constant of $966.6 \pm 0.5 \mathrm{~N} / \mathrm{m}$. Given a displacement resolution of $10 \mathrm{~nm}$, this translates to a load resolution of $9.7 \mu \mathrm{N}$. The resolution of the load cell can be further improved through use of a more compliant leaf spring, although any gain in resolution would decrease the maximum load that can be imposed. Conversely, the maximum load can be increased to $10 \mathrm{~N}$, the maximum value allowed by the piezo actuator, if a stiffer leaf spring is used. The various components of the tester were controlled and all signals were recorded with a personal computer equipped with a National Instruments USB-6281 data acquisition card (DAQ) and a Labview program. 


\subsection{Micro-heater with freestanding metal thin film}

Two possible techniques were considered for heating the sample during the test: 1) resistive heating of the sample by applying a current or a voltage $[31,32,35]$ and 2) sample heating using an external heater $[27-30,36,37]$. Resistive heating is straightforward to implement, but requires an electrically conductive sample and may result in temperature changes and a non-uniform temperature distribution during testing as the resistance of the sample changes. Once the sample starts to neck, current crowding results in localized heating and premature failure. External heating does not suffer from these drawbacks, but is more difficult to implement. Here we employ an external micromachined heater that is integrated with the sample. This approach minimizes sample handling, allows for in-situ temperature measurements, and results in a very uniform temperature distribution in the sample as long as the radiation heat losses are not too large.

Figure 2 shows the conceptual design of the micro-heater. The sample is supported by two micromachined heaters fabricated out of silicon. The micro-heaters use tungsten heating elements that also serve as resistive thermometers. A current passed through the heating elements heats the sample along with the heaters, while the resistance of the heating elements is measured in a four-point measurement setup. The temperature of the micro-heaters during the experiment is determined from the resistance of the heating elements, which is calibrated to temperature.

Preparing and handling thin-film samples for mechanical testing is difficult without damaging the sample [38, 39]. To facilitate sample handling, two sets of $\mathrm{Si}$ supports 
were designed on either side of the Si heaters. The outermost set of supports provides protection during sample handling. After the sample has been mounted in the tensile tester, the innermost V-shape supports protect the sample while the outermost supports are removed; these innermost supports are designed to easily snap when the sample is loaded in compression (Figure 2). 


\subsection{Thermal modeling of the micro-heater}

The temperature distribution in the $\mathrm{Si}$ micro-heaters and a typical sample was determined using the finite element method (FEM). The simulations were performed by solving the coupled thermal and electrical problem using the commercial code COMSOL Multiphysics $^{\circledR}$. Figure 3 shows a schematic of the three-dimensional mode used for the simulations. The tungsten heating element had a line width of $115 \mu \mathrm{m}$ and a total length of $16 \mathrm{~mm}$. Only one micro-heater and half of the sample (red box in Figure 2) were analyzed because of symmetry. The material properties used in the simulation are listed in Table I - the properties of the sample are typical for a $\mathrm{Cu}$ thin film. The temperature at the base of the micro-heater was fixed at $20^{\circ} \mathrm{C}$. Heat loss from the surface of the heater and the sample occurred only via radiation because the tester is typically placed in vacuum during operation. The simulations were performed for several electric potentials applied to the tungsten heating element. The results of the FEM analysis are shown in Figure 4. It is clear from the figure that the $\mathrm{W}$ heating element produces a very uniform temperature distribution in the sample even above $1000{ }^{\circ} \mathrm{C}$. Note that in the absence of convective heat losses, temperature non-uniformity in the sample can only arise because of radiative heat losses from the sample. These heat losses become significant only at temperatures in excess of $1200{ }^{\circ} \mathrm{C}$, which still results in a temperature non-uniformity of only $10^{\circ} \mathrm{C}$ within the film. The emissivity values used in the simulations were obtained from experimental measurements on similar thinfilm materials [40-45] and we believe these values to be representative metal thin films. The numerical values are quite small and this of course helps the temperature uniformity 
of the sample. The temperature measurement relies on a four-point measurement of the resistance of the heating element, which in turn is calibrated to temperature. Table II shows the difference between the volumetric average temperature of the $\mathrm{W}$ heating element and the $\mathrm{Cu}$ sample. It is clear that this difference is very small, less than $2 \%$, even at the highest temperature. 


\section{Experiment}

\section{1 Fabrication of the micro-heater fixture}

The integrated micro-heater and sample were prepared using standard photolithography and silicon micromachining techniques. As shown in figure 5(a), the process starts with a (100) Si wafer coated on both sides with a low-pressure chemical vapor deposited (LPCVD) $\mathrm{Si}_{3} \mathrm{~N}_{4}$ film. This wafer is first cleaved into $55 \times 55 \mathrm{~mm}^{2}$ square substrates. Both sides of one such substrate are coated with photoresist (Shipley, S1831) and exposed to UV for patterning. $\mathrm{Si}_{3} \mathrm{~N}_{4}$ is then selectively removed from the bottom side of the substrate in a reactive ion etch (RIE) process using $\mathrm{CF}_{4}$ (Figure 5(b)), and $700 \mathrm{~nm}$ of $\mathrm{W}$ is sputter deposited on the front side of the substrate. As illustrated in Figure 5(c), the $\mathrm{W}$ layer is defined using a lift-off procedure, and then coated with a $30 \mathrm{~nm}$ layer of $\mathrm{Si}_{3} \mathrm{~N}_{4}$ to prevent oxidation during high-temperature testing. To fabricate the thin-film sample, the front side of the wafer is again coated with photoresist. After exposing the photoresist, the sample of interest is deposited using sputter deposition and patterned using lift-off (Figure 5(d)). To make the sample freestanding, the Si substrate is etched using a $30 \%$ potassium hydroxide $(\mathrm{KOH})$ solution at $85^{\circ} \mathrm{C}$ (Figure $5(\mathrm{e})$ ). This $\mathrm{Si}$ etch is anisotropic with an etch selectivity of approximately 50:1 between the (100) and (111) crystal orientations. In a final step, the $\mathrm{Si}_{3} \mathrm{~N}_{4}$, which acts as a etch stop during $\mathrm{KOH}$ etching, is removed by RIE using $\mathrm{CF}_{4}$ (Figure 5(f)). Figure 6 shows the resultant micro heaters with a magnified view of the thin-film sample (Copper, in this figure). A total of 28 individual micro-heaters can be fabricated on a single $55 \times 55 \mathrm{~mm}$ Si substrate. The fabrication procedure is quite general and samples can be made out of any material 
that can be sputtered, evaporated, or printed, as long as there is sufficient etch selectivity with respect to $\mathrm{SiN}_{\mathrm{x}}$. It is also possible to fabricate the micro-heater fixture without sample and then mount a sample such as a nano-wire by attaching it to the edges of the micro heater using focused ion beam deposition.

\section{2 Specimen preparation and characterization}

For this study, thin-film samples of $\mathrm{Cu}$ were deposited using a DC magnetron deposition system (AJA International) with a base pressure of $1 \times 10^{-7} \mathrm{~Pa}$. The $\mathrm{Cu}$ source $(50.8 \mathrm{~mm}$ diameter) was powered at $200 \mathrm{~W}$ and the deposition proceeded in an atmosphere of $0.67 \mathrm{~Pa}$ of Ar. Samples were fabricated with widths of 100,150 , and $200 \mu \mathrm{m}$, and lengths of $1326 \pm 18$ and $2552 \pm 77$ $\mu \mathrm{m}$. Film thicknesses were measured using a profilometer (Veeco Dektak 6M). After deposition, all samples were annealed at $250^{\circ} \mathrm{C}$ for one hour in vacuum to increase the grain size of the film and to stabilize the microstructure. The grain structure of the samples was characterized using both a Zeiss Ultra55 field-emission scanning electron microscope (FE-SEM, Carl Zeiss Inc. Thornwood, NY) and a Zeiss NVision 40 Dual-Beam focused ion beam and scanning electron microscope (FIB/SEM). The crystallographic texture of the films was measured using electron backscattered diffraction (EBSD) inside a Zeiss Supra55 FE-SEM and confirmed with X-ray diffraction (XRD) using a Bruker D8 system.

Figure 7 shows EBSD and FIB images of the microstructure of the $880 \mathrm{~nm} \mathrm{Cu}$ film. At least five images (EBSD or FIB) were analyzed to determine the grain size of the films (Table III). The grain size was measured using the intercept method with twins counted as separate grains [47]. Note that the grain size was comparable to the film thickness when twins were not counted as grains, and that additional annealing at the maximum testing temperature $\left(430^{\circ} \mathrm{C}\right.$ in this study) did not further increase the grain size. This is consistent with the theoretical prediction that grain 
growth in a film is constrained by the thickness of the film [48]. EBSD images also provided the crystallographic texture of the films, which showed a strong (1 111 ) texture for all of the films. XRD further substantiated these results by showing strong ( $\left.\begin{array}{lll}1 & 1 & 1\end{array}\right)$ peaks for all films (Figure 8). 


\subsection{Experimental setup and procedure}

To perform a tensile test on a thin-film sample, the integrated micro-heater and sample are mounted in the tensile tester (Figure 9(a)) and placed inside the SEM (Figure 9(b)). The tensile tester is designed to fit inside the SEM chamber with extra space to rotate and control the $x, y$ and $z$-displacements of the tester. The tensile tester is connected to the control and data acquisition system outside the SEM using a specially designed flange with feed-through (Capacitec Vacuum Flange Kit KF40). While the tensile tester is intrinsically load-controlled, it is possible to perform experiments at constant displacement or strain rate using an appropriate feedback loop. In this study, tests were performed at a constant strain rate of $3.3 \times 10-5 s-1$. For each thickness, three samples were tested at room temperature. In addition, several samples were tested at a range of elevated temperatures. All results showed good repeatability.

High-temperature measurements were performed by connecting the current leads of the micro-heaters to a Protek 3030D dual dc power supply (Englewood, NJ) and the voltage sensing leads to the data acquisition system. The current applied to the heating elements also passes through a $10 \Omega$ precision resistor. The precise value of the applied current is determined by measuring the voltage drop across the precision resistor, while the resistance of the heating elements $\left(\mathrm{R}_{\mathrm{MH}}\right)$ is determined from the voltage drop across the voltage sensing leads (see Figure 3) of the heating elements. The temperature of the micro-heater is then calculated from $T=$ $T 0+R M H-R M H, 0 \lambda R M H, 0$ 
where $\lambda$ is the temperature coefficient of resistance of the heating element, $T_{0}$ is the ambient temperature, and $R_{M H, 0}$ is the resistance at $T_{0}$. Using this setup, we have been able to reach temperatures up to $700^{\circ} \mathrm{C}$. Note that only the micro-heaters are heated while the rest of the tester remains at room temperature. This approach virtually eliminates thermal drift in the test system. The absence of significant thermal drift is also confirmed prior to mechanical testing by monitoring the displacement signals with the micro-heaters turned on. 


\subsection{Temperature calibration}

Before high-temperature tensile measurements can be made, the micro-heaters need to be stabilized and calibrated. Stabilization occurred during the sample anneal, after which the resistivity of the heaters was typically below $3 \times 10-7 \Omega \cdot \mathrm{m}$, and very stable during high-temperature testing. The temperature coefficient of resistance of the micro-heaters was measured by placing a micromachined fixture on a hot plate and increasing the temperature to $180^{\circ} \mathrm{C}$ in steps of approximately $20^{\circ} \mathrm{C}$. During this process, the temperature of the micro-heater was measured with a thermocouple, while the resistance of the micro-heater was measured using a Keithley 2000 multimeter in a four-terminal setup. The temperature coefficient of resistance $\lambda$ was determined from a linear least squares fit of the resistance data as a function of temperature. The calibration measurements were generally very reproducible with a linearity better than $99.9 \%$. Experimental values of $\lambda$ averaged $(1.18 \pm 0.04) \times 10-3 K-1$. 


\section{Results and discussion}

\subsection{Stress-strain curve at room temperature}

Figure 10(a) shows an SEM image of an $880 \mathrm{~nm} \mathrm{Cu}$ sample before testing, while representative stress-strain curves are shown in figure 10(b). The value of Young's modulus obtained from the unloading curve is $131.1 \pm 0.2 \mathrm{GPa}$, in good agreement with previous studies [6, 49]. This value also agrees well with the modulus of $130.3 \mathrm{GPa}$ expected for $\mathrm{Cu}$ films with a strong (111) texture based on the single-crystal elastic constants of bulk $\mathrm{Cu}[50,51]$.

The stress-strain curves show a strong size effect - the yield strength of the $880 \mathrm{~nm}$ film is $302.6 \pm 7.4 \mathrm{MPa}$, while the value for the $385 \mathrm{~nm}$ film is approximately $510 \pm$ 10.3 MPa. These values are similar to measurements for freestanding $\mathrm{Cu}$ films performed by Xiang et al [6] using the bulge test, and to values obtained by Gruber et al [52] using the bulge test and a synchrotron-based tensile test on $\mathrm{Cu} /$ polyimide films. From the stress-strain curves it is evident that the $880 \mathrm{~nm}$ film is fully plastic, while the $385 \mathrm{~nm}$ film failed during the elastic-plastic transition. Agreement of both Young's modulus and yield strength with values obtained through different means, and the repeatability of the measurements indicate that the technique described here is a reliable method for measuring the stress-strain curves of thin films. 


\subsection{Stress-strain curve at elevated temperatures}

Figure 11 shows the stress-strain curves for the 880, 385, and $465 \mathrm{~nm}$ films at various temperatures. As the temperature increases, two features stand out: the initial and unloading slopes of the stress-strain curves decrease dramatically, as do the yield strengths (Table III). The slope decreases from $131 \mathrm{GPa}$ at room temperature to $92 \mathrm{GPa}$ at $430^{\circ} \mathrm{C}$, while the yield strength decreases from $303 \mathrm{MPa}$ to $72 \mathrm{MPa}$ over the same temperature range. The reduction in slope is consistent with experiments on bulk materials $[53,54]$ at elevated temperature. It is instructive to compare the results in Figure 11 with substrate curvature measurements performed on $\mathrm{Cu}$ films. Substrate curvature measurements provide the stress in a coating on a substrate. If the substrate is heated, thermal mismatch between the film and substrate can cause the film to flow plastically. In this case, the film stress provides a measure for the yield strength of the film. Keller et al [8] reported that the compressive stress in unpassivated $\mathrm{Cu}$ films on $\mathrm{Si}$ substrates decreased in absolute value with increasing temperature and attributed this to operation of diffusional creep as the dominant deformation mechanism [54]. In their experiment, a relatively low and constant stress was reached, $-25 \mathrm{MPa}$ for a $1 \mu \mathrm{m}$ film and $-60 \mathrm{MPa}$ for a $600 \mathrm{~nm}$ film above $210{ }^{\circ} \mathrm{C}$. Figure 11(a) shows a plateau stress of approximately $70 \mathrm{MPa}$ for $880 \mathrm{~nm}$ films tested above $300{ }^{\circ} \mathrm{C}$. 


\subsection{Temperature-dependent elastic behavior}

Early studies of bulk single crystal and polycrystalline copper reported temperaturedependent elastic constants [53]. Interestingly, Young's modulus of polycrystalline copper showed a significantly steeper decline with increasing temperature than the value obtained by appropriate averaging of single-crystal constants. In particular, the experimental temperature coefficient of Young's modulus was $-4.8 \times 10^{-4} \mathrm{~K}^{-1}$ for polycrystalline copper, while the temperature coefficient based on the single-crystal constants was $-3.6 \times 10^{-4} \mathrm{~K}^{-1}$. The discrepancy between these values was clearly associated with the presence of grain boundaries in the polycrystalline material and was interpreted as a softening of the grain boundaries at elevated temperature. The temperature coefficient measured in this study is $-7.3 \times 10^{-4} \mathrm{~K}^{-1}$, approximately twice as large as the value based on the single-crystal constants. Evidently this enhanced temperature dependence must be due to the very small grain size and the ensuing large volume fraction of grain boundaries in the copper films.

Deformation by grain boundary sliding is a possible mechanism for the softening effect of the grain boundaries [55-58]. During grain boundary sliding, an internal back stress builds up at the triple junctions of the grain boundaries that eventually stop the sliding. This internal stress drives the recovery process during unloading and may result in a reduced modulus. At elevated temperature, grain boundary sliding must be accompanied by diffusion to ensure compatibility between grains. The relaxation time $\tau$ for such a diffusion-controlled sliding process is given by [59-61]

$$
\tau=14 k T \mu \Omega b 2 d \delta D 0, g b \exp Q g b R T
$$

where $\mu$ is the shear modulus, $d$ is the grain size, $Q_{g b}$ and $D_{0, g b}$ are the activation 
energy and pre-exponential coefficient for the grain boundary diffusivity, $b$ is the Burgers vector, $T$ is the absolute temperature, $k$ is Boltzmann's constant, and $\delta$ is the width of the grain boundary (see Table IV for numerical values of these parameters). Relaxation times calculated for each experiment are shown in Figure 12. If the relaxation time is much shorter than the time scale of a given tensile test, grain boundary sliding occurs during the test. Figure 12 clearly demonstrates that the relaxation time at room temperature is much larger than the duration of the experiments, so that any effects of grain boundary sliding can be ruled out in this case. It is also evident that grain boundary sliding is a plausible explanation for the reduction in the initial slopes and the unloading slopes at elevated temperature. 


\subsection{Temperature-dependent yield strength}

The temperature-dependent mechanical behavior of thin metal films has been explained using several deformation mechanisms including thermally activated dislocation glide, grain boundary diffusional creep, and dislocation-based creep [18, 22, 29, 62, 63]. In an attempt to identify the mechanism that controls high-temperature deformation in copper thin films, we calculate the activation energies of several different deformation mechanisms assuming they control the deformation in our experiments and compare them with their bulk value (see Table IV for numerical values of material parameters used in this calculation). If the calculated activation energy is on the order of, or greater than, the bulk value, the deformation mode under consideration is likely active.

If deformation is controlled by thermally activated dislocation glide, the strain rate $\varepsilon d g$ is given by $[18,54]$

$$
\varepsilon d g=\varepsilon 0 \text { exp }-\Delta F d g k T 1-s \sigma \tau
$$

where $\varepsilon 0$ is a characteristic constant that depends on the initial dislocation density, $\Delta F d g$ is the activation energy at zero stress, $\sigma$ is the applied stress, $\tau$ is the critical resolved shear stress, which can be interpreted as the yield strength at $0 \mathrm{~K}$, and $s$ is the Schmid factor for single crystals or materials with a strong texture. Following calculations by Gruber et al. [18], $\Delta F d g$ is

calculated from Eq. (5) by replacing the strain rate $\varepsilon d g$ with the experimental strain rate and by using the experimental yield strength for $\sigma$. This procedure results in the activation energy 
required for thermally activated dislocation glide to explain the experimental data. The results of this calculation are tabulated in Table V.

The second mechanism we considered is creep by grain boundary diffusion, a mechanism originally postulated by Gibbs [62]. In this case, the strain rate $\varepsilon g b$ is given by

$$
\varepsilon g b=A g b \delta D 0, g b k T \Omega d h 2 \sigma \exp -Q g b R T
$$

where $A g b$ is a constant equal to $12, d$ is the grain size, and $h$ the film thickness. The activation energies for creep by grain boundary diffusion calculated using the same procedure as before are tabulated in Table V.

Finally, power law creep with diffusion assisted climb of dislocations over obstacles is considered [54, 63-65]. The power law creep model is usually coupled with lattice diffusion for high-temperature creep and dislocation core diffusion for low-temperature creep. In our calculations, only lattice diffusion was considered, because core diffusion resulted in an activation energy that was much too low [63]. The creep rate in case of power law creep with lattice diffusion can be written as

$$
\varepsilon v=\mathrm{A} b \mu \mathrm{D} 0, v k T \sigma \mu 4.8 \exp -Q v R T
$$

where $A$ is a constant of $1.79 \times 107, D 0, v$ the pre-exponent coefficient for lattice diffusion, and

$Q v$ is the activation energy for lattice diffusion. Equation (7) was used to calculate the activation energies for power law creep using the same procedure as before.

The activation energies required for the various deformation mechanisms are listed in Table V, along with experimental values obtained for bulk materials. The table shows that the activation energies increase with increasing test temperature for all three mechanisms. However, the activation energy for thermally activated glide stays well below the bulk value, even at the 
highest temperature, making this mechanism less likely to occur. Power law creep or creep by grain boundary diffusion, on the other hand, have activation energies that are comparable to or exceed the bulk values at elevated temperature, and are therefore likely to occur. Thus, it is reasonable to assume that deformation occurs via creep induced by grain boundary diffusion or dislocation climb [60]. Figure 13 shows an SEM micrograph of region where the $880 \mathrm{~nm}$ sample failed taken at the conclusion of the test at $332^{\circ} \mathrm{C}$. Evidently fracture occurred along the grain boundaries. The micrograph also shows extensive grain boundary voiding, indicative of significant grain boundary diffusion. These observations and the analysis are consistent with a recent study on Au films that identified grain boundary sliding as the dominant deformation mechanism, with an increasing contribution of dislocation climb at elevated temperature [29]. While more extensive mechanical characterization may be required to provide detailed insight in the temperature dependence of plastic flow in thin films, the merit of the approach is clear. 


\section{Summary}

We have built an in-situ SEM mechanical tester for determining mechanical properties of nano/micro thickness thin films. The displacement resolution of the tester is $10 \mathrm{~nm}$ with $250 \mu \mathrm{m}$ stroke and the load resolution is $9.7 \mu \mathrm{N}$. A micromachined heater is also introduced for mechanical testing at elevated temperatures inside the SEM. Each microheater consists of a tungsten heating element, which also serves as a temperature gauge, and a freestanding thin film for mechanical measurement. FEM thermal analysis was performed to confirm a homogeneous temperature profile in the freestanding thin film and to estimate the temperature during Joule heating. Stress-strain curves measured at room temperature show high repeatability with Young's modulus and yield stress similar to results reported in the literature. Tensile testing at elevated temperature reveals a large decrease in the yield strength, as well as a significant decrease in the initial loading and unloading slopes. We attribute this difference to thermally activated deformation mechanisms such as grain boundary sliding and dislocation climb aided by lattice diffusion at elevated temperatures. These experiments demonstrate the capability of our testing method to investigate temperature-dependent mechanical behavior of thin films. 


\section{Acknowledgments}

The work presented in this paper was supported by the Air Force Office of Scientific Research under Grant FA9550-12-1-0098 (program manager Dr. Ali Sayir) and by the National Science Foundation under Grant DMR-0906892. This work was also supported by the National Research Foundation of Korea (NRF) grant funded by the Korea government (MEST) (No. 2011R1A2A2A02649388) and by the Korea Science Research Program through the National Research Foundation of Korea (NRF) funded by the Ministry of Education, Science and Technology (no. KOSEF 2009-0085880). Uchic and Shade further acknowledge support from the Air Force Office of Scientific Research (program manager Dr. Ali Sayir) and the Materials \& Manufacturing Directorate of the Air Force Research Laboratory. Uchic and Shade would also like to acknowledge useful discussions with R. Wheeler (UES Inc., MicroTesting Solutions LLC). The tensile samples were fabricated at the Center for Nanoscale Systems, a member of the National Nanotechnology Infrastructure Network, which is supported by the National Science Foundation under NSF Award ECS-0335765. The Center for Nanoscale Systems is part of the Faculty of Arts and Sciences at Harvard University. 


\section{References}

[1] Gleskova H, Cheng IC, Wagner S, Sturm JC, Suo ZG. Sol Energy 2006;80:687.

[2] Jiang FK, Lee GB, Tai YC, Ho CM. Sensor Actuat a-Phys 2000;79:194.

[3] Shamanna V, Das S, Celik-Butler Z, Butler DP, Lawrence KL. J Micromech Microeng 2006;16:1984.

[4] Bonderover E, Wagner S. Ieee Electr Device L 2004;25:295.

[5] Ma Q, Clarke DR. J Mater Res 1995;10:853.

[6] Xiang Y, Vlassak JJ. Acta Mater 2006;54:5449.

[7] Haque MA, Saif MTA. Acta Mater 2003;51:3053.

[8] Keller RM, Baker SP, Arzt E. J Mater Res 1998;13:1307.

[9] Stolken JS, Evans AG. Acta Mater 1998;46:5109.

[10] Read DT. Int J Fatigue 1998;20:203.

[11] Zhang GP, Volkert CA, Schwaiger R, Wellner P, Arzt E, Kraft O. Acta Mater 2006;54:3127.

[12] Schwaiger R, Kraft O. Acta Mater 2003;51:195.

[13] Sim G-D, Lee Y-S, Lee S-B, Vlassak JJ. Materials Science and Engineering: A 2013;575:86.

[14] Vlassak JJ, Nix WD. J Mater Res 1992;7:3242.

[15] Hommel M, Kraft O. Acta Mater 2001;49:3935.

[16] Espinosa HD, Prorok BC, Fischer M. J Mech Phys Solids 2003;51:47.

[17] Uchic MD, Dimiduk DM, Florando JN, Nix WD. Science 2004;305:986.

[18] Gruber PA, Olliges S, Arzt E, Spolenak R. J Mater Res 2008;23:2406.

[19] Volinsky AA, Moody NR, Gerberich WW. J Mater Res 2004;19:2650.

[20] Smith JF, Zheng S. Surface Eng 2000;16:143.

[21] Flinn PA, Gardner DS, Nix WD. Ieee T Electron Dev 1987;34:689.

[22] Keller RM, Baker SP, Arzt E. Acta Mater 1999;47:415.

[23] Sim GD, Won S, Jin CY, Park I, Lee SB, Vlassak JJ. J Appl Phys 2011;109.

[24] Sim GD, Hwangbo Y, Kim HH, Lee SB, Vlassak JJ. Scripta Materialia 2012;66:915.

[25] Lu NS, Wang X, Suo ZG, Vlassak J. Appl Phys Lett 2007;91:221909.

[26] Xiang Y, Li T, Suo ZG, Vlassak JJ. Appl Phys Lett 2005;87.

[27] Kalkman AJ, Verbruggen AH, Janssen GCAM. Rev Sci Instrum 2003;74:1383.

[28] Haque MA, Saif MTA. Thin Solid Films 2005;484:364.

[29] Karanjgaokar NJ, Oh CS, Lambros J, Chasiotis I. Acta Mater 2012;60:5352.

[30] Smolka M, Motz C, Detzel T, Robl W, Griesser T, Wimmer A, Dehm G. Rev Sci Instrum $2012 ; 83$.

[31] Zupan M, Hemker KJ. Mat Sci Eng a-Struct 2001;319:810.

[32] Zupan M, Hayden MJ, Boehlert CJ, Hemker KJ. Exp Mech 2001;41:242. 
[33] Merchant HD, Khatibi G, Weiss B. J Mater Sci 2004;39:4157.

[34] Cheng YW, Read DT, McColskey JD, Wright JE. Thin Solid Films 2005;484:426.

[35] Oh CS, Sharpe WN. Sensor Actuat a-Phys 2004;112:66.

[36] Kang W, Saif MTA. J Micromech Microeng 2011;21.

[37] Kang WM, Saif MTA. Adv Funct Mater 2013;23:713.

[38] Read DT, Dally JW. J Mater Res 1993;8:1542.

[39] Keller RR, Phelps JM, Read DT. Mat Sci Eng a-Struct 1996;214:42.

[40] Vandenabeele P, Maex K. 1991:316.

[41] Lienhard JH. A heat transfer textbook. Mineola, N.Y.: Dover Publications, 2011.

[42] Cheng SX, Cebe P, Hanssen LM, Riffe DM, Sievers AJ. J Opt Soc Am B 1987;4:351.

[43] Jacquot A, Chen G, Scherrer H, Dauscher A, Lenoir B. Sensor Actuat a-Phys 2005;117:203.

[44] CRC handbook of chemistry and physics. Cleveland, Ohio: CRC Press, 1977. p.v.

[45] Window B, Harding G. J Opt Soc Am 1981;71:354.

[46] McCluskey PJ, Vlassak JJ. Thin Solid Films 2010;518:7093.

[47] Xiang Y, Tsui TY, Vlassak JJ. J Mater Res 2006;21:1607.

[48] Thompson CV. Annu Rev Mater Sci 2000;30:159.

[49] Espinosa HD, Prorok BC, Peng B. J Mech Phys Solids 2004;52:667.

[50] Simmons G, Wang H. Single crystal elastic constants and calculated aggregate properties: a handbook. Cambridge, Mass.,: M.I.T. Press, 1971.

[51] Huang H. Mechanical properties of free-standing polycrystalline metallic thin films and multilayers. vol. 9832391. United States -- Massachusetts: Harvard University, 1998. p.174.

[52] Gruber PA, Bohm J, Onuseit F, Wanner A, Spolenak R, Arzt E. Acta Mater 2008;56:2318.

[53] Ledbetter HM, Naimon ER. Journal of Physical and Chemical Reference Data 1974;3:897.

[54] Frost HJ, Ashby MF. Deformation-mechanism maps : the plasticity and creep of metals and ceramics. Oxford Oxfordshire ; New York: Pergamon Press, 1982.

[55] Rosenhain W, Ewen D. J I Met 1912;8:149.

[56] Zener C. Phys Rev 1941;60:906.

[57] Ke TS. Phys Rev 1947;71:533.

[58] Nowick AS, Berry BS. Anelastic relaxation in crystalline solids. New York,: Academic Press, 1972.

[59] Bohn HG, Prieler M, Su CM, Trinkaus H, Schilling W. J Phys Chem Solids 1994;55:1157.

[60] Raj R, Ashby MF. Metall Trans 1971;2:1113.

[61] Ashby MF, Raj R, Gifkins RC. Scripta Metall Mater 1970;4:737.

[62] Gibbs GB. Philos Mag 1966;13:589.

[63] Emery RD, Povirk GL. Acta Mater 2003;51:2079.

[64] Raj R, American Society for Metals. Materials Science Division. Seminar Committee. Flow and fracture at elevated temperatures : papers presented at the 1983 ASM Materials Science Seminar, 1-2 
October 1983, Philadelphia, Pennsylvania. Metals Park, Ohio: ASM, 1985.

[65] Chandler HD. Mat Sci Eng a-Struct 2010;527:6219. 